\title{
SECTION \\ OF PHOTOGRAPHY AND MICROSCOPY
}

(Stated meeting held Thursday, January 7, Igog.)

\section{THE DAGUERROTYPE, THE AMBROTYPE, AND THE PHOTOGRAPH.}

\author{
BY \\ WILLIAM O. GRIGGS, M.D., \\ Member of the Institute.
}

Tere word 'photograph' is obtaine 1 from two Greek wordsphotos, light, and graphos, to write. Photography is the art of producing pictures by the action of certain sensitive substances undet the action of light. It is said to have sprung from the discovery, some 300 years ago, that the luna cornea of the alchemists (fused silver chloricle) would darken on exposure to light. Nothing more was known about this until in 1777 Scheele, the Swedish chemist, noticed that the power which produced this darkening resided chiefly in the violet end of the solar spectrum; this led to the use of nonactinic or red light in which to handle the sensitive plates, especially while developing and fixing them. The difficulty of fixing the pictures was one of the early troubles experienced; this was finally overcome by Sir John Herschel, who suggested the use of hyposulphite of soda.

The photographic picture is obtained in the daguerrotype process on polished metal plates, either of silver or of copper coated with silver.

Calotype is produced on paper,

Albumin on a film of albumin on glass,

Collodion on a film of collorion on glass,

Gelatin on a film of gelatin on giass.

The daguerrotype process was discovered by Niepce and Daguerre, and in short is as follows: A silver or silvered copper plate is highly polished and placed in a rlark room on a china dish containing iodine. The vapor of this strbstance combines with the silver of the plate and produces iodicle of silver, a sub- 
stance sensitive to light. This wonderful discovery, like many others, was the result of an accident. Daguerre had iodized some silver plates to use for an experiment he was making and carelessly left a metal spoon lying on one of them; upon raising the spoon some time afterwards, he found its image clearly impressed upon the plate. From this he learned that iodide of silver was sensitive to light, and after a few more experiments the so-called daguerrotype was produced.

One of the first difficulties that Daguerre encountered was to have the plate properly polished. This was finally successfully accomplished by August Brassart, a silversmith of Paris, who sought out Daguerre and volunteered his services. It is stated

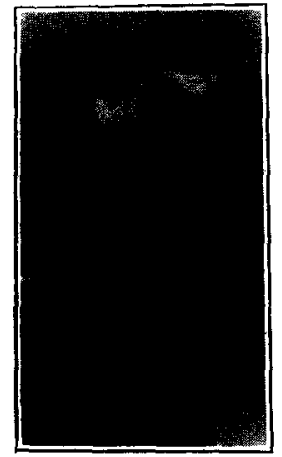

Tree-frog snapshot, Seeds $26 \times$ plate. By Dr. Wm. O. Griggs.

that when the first successful picture was made, Daguerre embraced his assistant and fainted in his arms. Brassart died in St. Louis, Mo., early in August of this present year (I908) and a short historical notice of him appeared in the Philadelphia Inquirer of August Io, I908.

The next difficulty that beset Daguerre was properly to develop the picture. The discovery which solved this difficulty was also the result of an accident. He had made a number of exposures and was as many times discouraged by his want of success in developing his pictures. One day he placed an exposed plate in a closet, intending at some future time to take it out and clean it and resensitize it. After leaving it there for a considerable time, he removed it, and was very much surprised to find the picture beautifully developed. But as there were a number of articles in the closet he did not know to which to attribute the 
wonderful result. He then began to remove the articles one by one and after each removal he placed an exposed plate in the closet, and still the development went on. Finally after having removed everything he again placed an exposed plate in the closet and was again surprised to find the picture perfectly developed. After making a critical examination of the interior he discovered that some mercury had been spilled on the floor and rightly conjectured that the vapor of the mercury had caused the much-

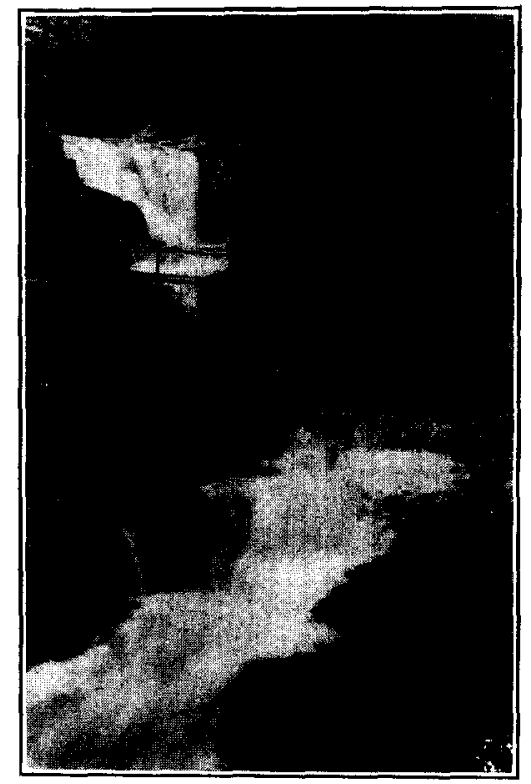

Winona Falls Nos. I, 2 and 3 , Pike Co., Pa. Snapshot, Carbutt's Eclipse plate 27 By Dr. Wm. O. Griggs.

desired result; and further experiments proved this to be true. The picture was finally fixed or made permanent by dipping it into a weak solution of hyposulphite of soda.

To Giambattista della Porta, a Neopolitan philosopher of the latter part of the sixteenth century, belongs the honor of having been the first to contribute to the optics of photography an apparatus by which the size of the picture and its proper registration on the plate could be controlled. This was called the camera obscura, or camera as we term it at the present time, an article which is so common to you all that it is not necessary to describe it. 
There is some controversy about the early history of the daguerrotype. It was so slow a process that it was possible to use it only for still-life pictures until the discovery that bromine used instead of iodine for sensitizing the plates rendered them speedy enough to permit of making portraits. The honor of this discovery undoubtedly belongs to Dr. Paul Beek Goddard, of Philadelphia, as in a paper read by him before the American Philosophical Society in I843, he described the bromide process, exhibiting at the same meeting a daguerrotype which he said

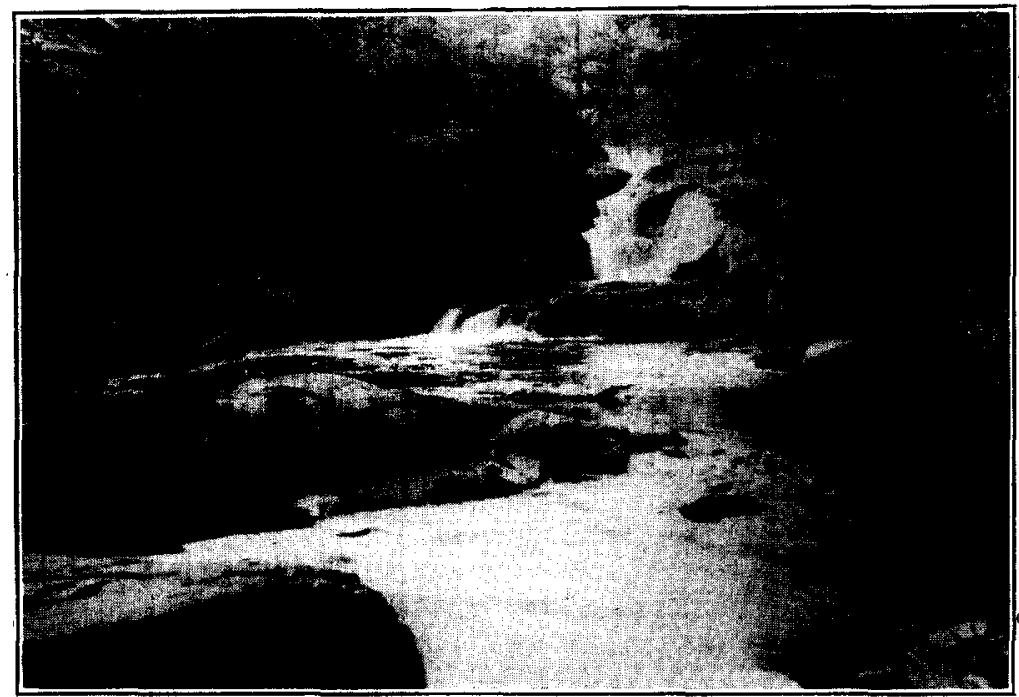

Winona Falls No. 5, Pike Co., Pa. Snapshot, Carbutt's Eclipse plate 27.

he nade by that process in December, I 839 . Dr. Goddard was known to be a man of sterling integrity and truthful in his statements. This account is published in the Transactions of the American Philosophical Society, vol. 3, page I8o. This society was composed of men of eminence in science and character, who would not allow any statement of a doubtful nature to appear on the pages of their journal.

The calotype process was the invention of $\mathrm{Mr}$. W. H. Fox Talbot. It consists in spreading on a sheet of paper first a solution of jodide of potassium and then a solution of nitrate of silver; these react and produce iodicle of silver in the pores of the paper. The paper is then well washed in water, contained in a porcelain basin, to remove the excess nitrate of silver. If this 
paper is exposed to light. the iodide of silver will blacken. The picture is fixed by the use of hyposulphite of soda. The calotype pictures are all what are called indirect or negative pictures, and Talbot was the first to use the terms negative and positive.

The albumin process consists in dissolving a small quantity of iodide of potassium in properly prepared albumin obtained from white of egg. This is spread on a well-cleaned plate of glass, the dried glass is immersed in a solution of nitrate of silver, exposed to the light in a camera, and developed in the same way

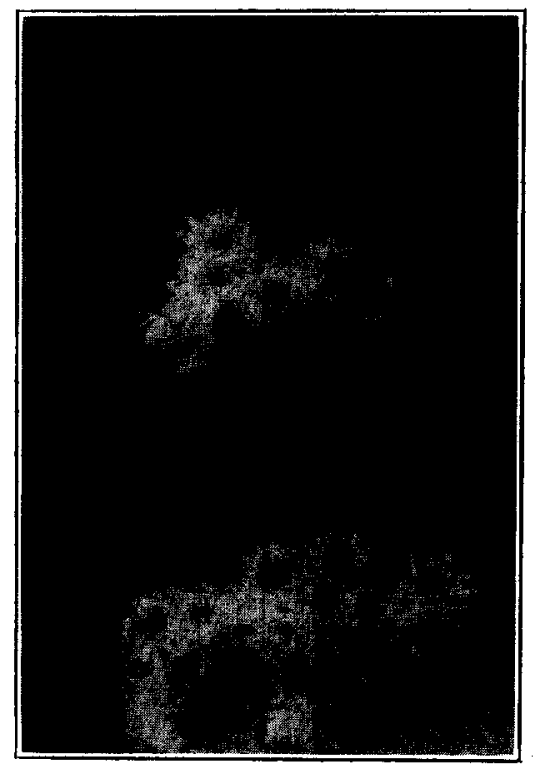

Water lilies from Echo Lake, Monroe Co., Pa. Exposture I second, Stanley plate 50. By Dr. Wm. O. Griggs.

as the calotype; that is, by using a mixture composed of a solution of gallic acich and a weak solution of nitrate of silver to which a little acetic acid has been added; it is then fixed as usual with hyposulphite of soda. The advantages of this process are that the details are finer and the objectionable grain of the paper is avoided. It is not suitable for portraits, as it is not very sensitive, requiring about ten minutes in a good light to produce an impression.

The collodion process, which employs a film of collodion properly treated with the iodides and then immersed in a nitrate of silver solution, has the great advantage of being at least sixty 
times more sensitive than the albumin process and much easier of execution.

The next successful style of picture after the daguerrotype was the ambrotype, from the Greek words ambrotos, immortal, and typos, an impression. This was made on glass on which a properly prepared collodion had been spread, the lights being represented by silver and the shadows produced by a dark background visible through the unsilvered portions of the glass. The ambrotype collodion was composed of

Collodion $\ldots \ldots \ldots \ldots \ldots \ldots \ldots \ldots \ldots \ldots \ldots \ldots \ldots$ oz.

Bromo-iodide of silver ........................

Hydrobromic acid $\ldots \ldots \ldots \ldots \ldots \ldots \ldots \ldots \ldots, 6$ drops

The manner of procedure is to make a bath containing 40 grains of nitrate of silver to the ounce of water. The bromide of silver is marle by mixing

Bromide of potassium $\ldots \ldots \ldots \ldots \ldots \ldots \ldots \ldots, 80$ gr.

Nitrate of silver ........................... $80 \mathrm{gr}$.

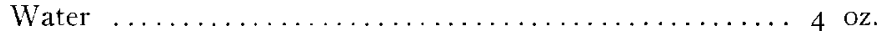

Dissolve the salts separately, then mix and wash in three changes of water and two of alcohol, then powder iodide of potassium I ounce and dissolve in alcohol 8 ounces and add to the above mixture.

Hydrobromic acid is made by taking

Alcohol (95 per cent.) .................... 4 oz.

Water (distilled) ....................... I oz.

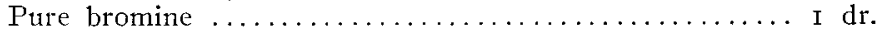

Shake well and add to the collodion. The collodion is flowed over the glass plate and the plate dipped into the nitrate of silver bath. It is then exposed in the camera, developed with either gallic acid or sulphate of iron, and fixed in the usual way.

The first photography such as is used at the present daythe making of a negative in the camera first and then printing the positive picture from that negative-was done by what is known as the wet-plate process, so called because the plate was sensitive only while wet. This method was as follows: After cleaning the glass thoroughly it was given a coat of albumin by pouring over the plate a mixture of well-beaten white of egg and water. The plates after having been dried were put away and secured from dust. It was found that the collodion used in 
the next part of the process flowed more evenly and easily over a plate thus prepared. The collodion was prepared in the usual way by dissolving gun cotton in a mixture of alcohol and ether. The proportions are:

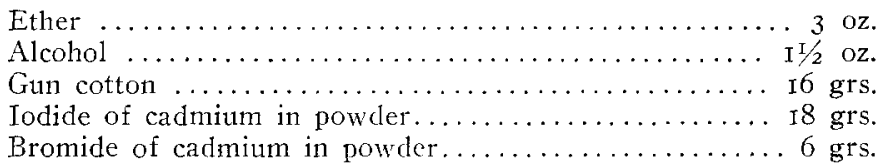

This was then flowed over the plate (by pouring it on the middle and then tilting the plate in different directions until entirely covered, when the collodion was poured off from the lower righthand corner) and after it was set it was lowered into a bath composed of 2 ounces of pure crystallized nitrate of silver and 24 ounces of distilled water. The plate was raised from time to time from the bath and examined ; if it presented a greasy appearance or showed lines upon it, it was returned to the bath until it presented a smooth homogeneous surface. It hat to be placed in the camera and exposed at once while still wet. The plate w'as then immediately developed by pouring over it a solution composed of

Protost1phate of iron $\ldots \ldots \ldots \ldots \ldots \ldots \ldots \ldots \ldots \ldots$. oz.

Acetic acid ........................... I2 drops

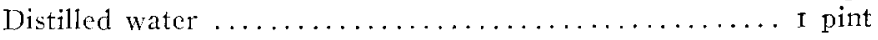

after which it was fixed in a bath composed of

Hyposulphite of soda ...................... 3 oz.

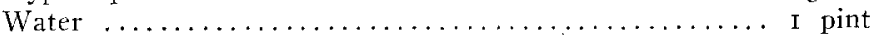

This process requires such cumbrous apparatus that it is unsuited to the needs of the present day and is very little used except for lantern slides and window transparencies.

Since the advent of the gelatin dry plate, photography has made wonderful strices both in the picturesque and the useful. One of the good features of these plates is that they can be transported to great distances. They may be developed at leisure even months after having been exposed. Another great advantage over the old wet plate is their great rapidity. Until very quick plates were made it was impossible to correctly picture animals in motion. The first successful pictures of this kind were made by Mr. Muybriclge. Some of our recent snapshots 
of horse-races prove the old idealized pictures of trotting horses to be mere caricatures of the truth, as these old pictures show the horses in all sorts of impossible attitudes. Rapid plates are also of use in photographing lightning flashes correctly-some of Doré's illustrations of lightning in Dante's "Inferno" resemble a zigzag staircase more than anything else. One of the pioneers in making pictures of lightning flashes was Mr. W. N. Jennings, of Philadelphia.

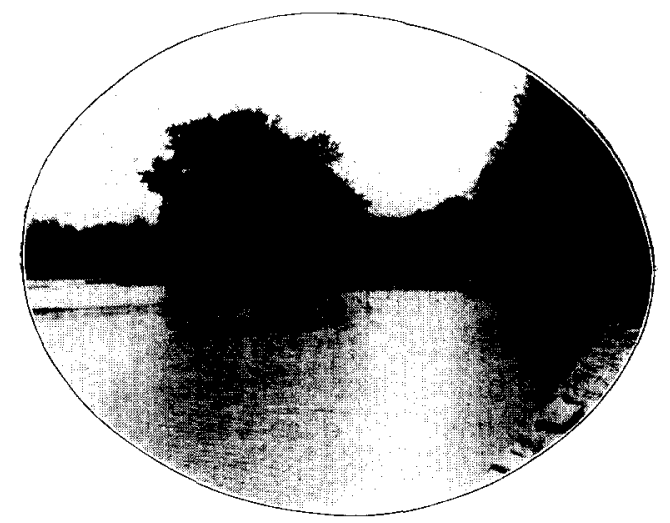

Peters Island, Schuylkill River. Snapshot taken against the sunlight, Carbutt's Eclipse 27 By Dr. Wm. O. Griggs.

The first manufacturer of dry plates in Philadelphia was the late Mr. John Carbutt, a member of the Franklin Institute and one of our colleagutes in the photographic section. Dry plates are made in three classes - slow, medium fast, and very fast. The very slow chloride plates are used for lantern slides and window transparencies; the medium fast, for landscapes, machinery, and architectural subjects, etc.; while the most rapid plates are used for portrait and snapshot or instantaneous work, and X-ray pictures.

Window transparencies and lantern slides are made in two ways. One is to place the negative in a window with a sky exposure or to back it up with a ground glass and then to photograph the negative on the sensitive plate in the camera. Another and I think a surer and quicker process is to print the picture on the sensitive plate by contact and then develop it in the usual way. This is done by placing the negative in a printing frame and placing the sensitive side of the dry plate in contact 
with it in a manner similar to that of printing on paper. The amount of exposure can be determined by experience only, as it varies in duration. If the plate is exposed at a distance of 18 inches from an ordinary 6 feet gas burner the variation will be from 20 to 35 seconds, according to the density of the negative.

The developer which I have found to be the most successful is made after the following formula:

No. I.

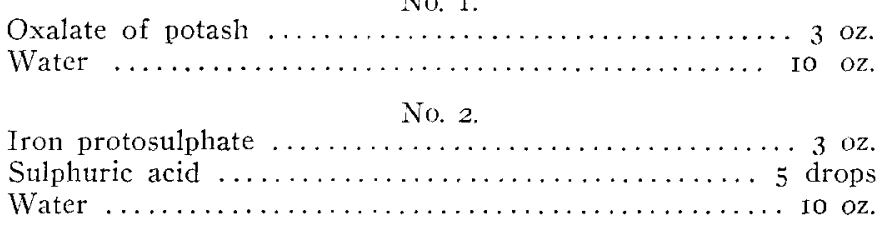

Use 3 parts No. I and I part No. 2. Should the plate develop too fast, add a few drops of a Io per cent. solution of bromide of potassium.

In making up this developer care should be taken not to forget to add the sulphuric acid to the iron solution and to test it with litmus paper to see that it is strongly acid. If it is found upon mixing the two solutions that a brick-red precipitate is thrown down, the mixture must be thrown away, for if used it would ruin the plate. After being well washed the plate should be fixed in a solution composed of I pound of hyposulphite of soda and I gallon of water.

The use of very rapid plates with the flash-light has made it possible to picture the inside of mines and other very dark places; and they have proven a boon to astronomers, enabling them to picture the stars with great accuracy. A number of important astronomical discoveries have been made by the aid of photography. Many new stars have been discovered on the negatives that were unknown and invisible to the naked eye or the telescope. Wonderful and valuable pictures of eclipses of the sun, even to the extent of moving pictures, have been made. The transit of Venus has been photographed by its aid, and extra satellites to some of the planets have been discovered. As the earth is constantly in motion a carefully regulated clockwork is attached to the camera in order to keep the celestial object properly registered on the sensitive plate. Another of the interesting and educational features to which photography has been 
applied are the now almost universal life-motion pictures. Some of them are of course made up to illustrate the subject shown, others showing the various industries and modes of life in this and foreign countries are natural and are not only interesting but also instructive to those whose means will not allow them to travel to distant lands. Another very interesting form of picture is the stereograph. This should properly be made with a pair of matched lenses. A division is placed in the camera, the two pictures taken on the same plate, and after being printed, they are cut apart and transposed, as the lenses reverse every-

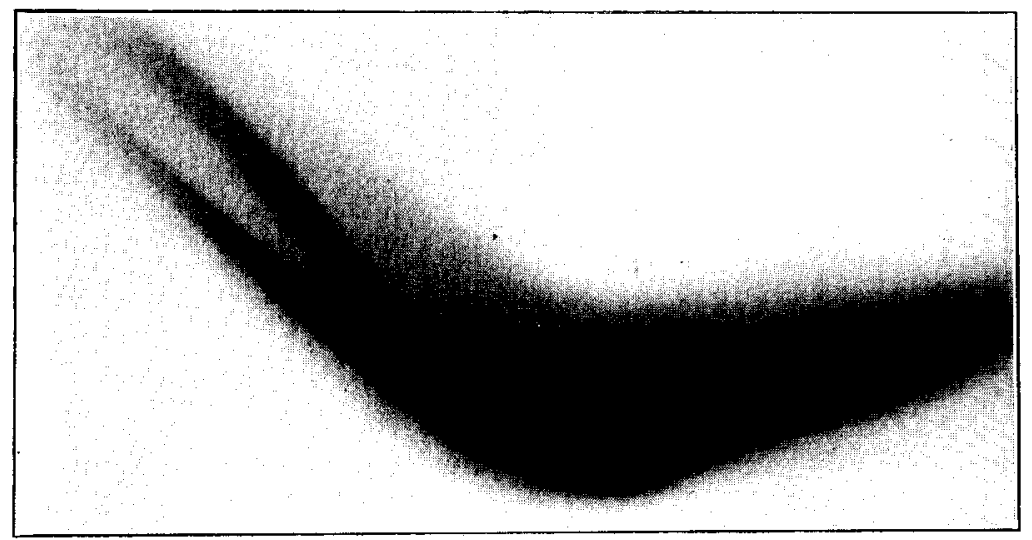

X-ray photograph of forward dislocation of the elbow joint, rare form, on X-ray plate. By William B. Griggs, M.D., Children's Homeopathic Hospital, Philadelphia.

thing. This is the ideal form of picture, as it gives the effect of a picture seen with both eyes and everything stands out separately, whereas the photograph taken with one lens presents simply a flat surface. The proper manner in which to take a picture of a flash of lightning is to focus the camera during the day on some distant object, then during a thunder storm at night, if a spot is noticed where lightning-flashes occur quite frequently, place the camera so as to command a view of them, draw the slide out of the plate-holder, uncap the lens and trust to luck; for the capturing of a picture of a flash of lightning is really a matter of chance. Since the advent of balloons snapshot pictures have been used for topographical purposes and also during war times in making pictures of the enemy's position and the arrangement of fortifications and distribution of troops. 
The latest and perhaps the most valuable and humanitarian use to which photography has been applied is in connection with the X-ray work. Here the two most comprehensive sciences, photography and electricity, go hand in hand for the benefit and instruction of humanity. By the use of these two great agents, deep-seated and obscure injuries have been pictured and a correct diagnosis made; bullets and other foreign bodies have been located and their removal made comparatively easy; and recently by the use of very rapid plates and large induction coils instaneous pictures showing the opening and closing of the valves of the heart have been made.

\section{A REVIEW OF THE COAL-MINING INDUSTRY IN Igo8.}

DECREASE IN PRODUCTION.

From reports received by the United States Geological Survey it might be inferred that a most effective method of conserving the coal resources of the country is to develop a financial panic, for one result of the depression that followed the panic of October, I907, appeared in decreased production of coal in the United States in I908-a decrease of 15 to 20 per cent. as compared with the production of the preceding year.

In I907 the production reached the unprecedented total of $480,363,424$ short tons, of which 394,759, I I 2 short tons were bituminous coal and lignite and 85,604,3I2 short tons were Pennsylvania anthracite. Letters received from State officials and others closely in touch with the coal-mining industry in the several States indicate that the bituminous coal production in Igo8 was between $320,000,000$ and $330,000,000$ tons, or practically $70,000,000$ tons less than in 1907.

The railroad shipments of anthracite in 1908 amounted to $64,237,076$ long tons, or $71,945,525$ short tons, as compared with $67,109,393$ long tons, or $75,162,510$ short tons, in 1907 , indicating a decrease in the shipments of this product, which, except for the very smallest sizes, is now used almost exclusively for domestic purposes, of $2,872,3 \mathrm{I} /$ long tons, or $3,217,005$ short tons. This would indicate a decrease in the total production of anthracite of $3,580,000$ short tons.

In the bituminous regions the effects of the panic were most seriously felt in the coking branch of the coal-mining industry, the Connellsville and the Lower Connellsville districts of Pennsylvania, the principal coke-producing centres, reporting a decrease in output amounting to nearly 5o per cent.

In Utah, where the smallest percentage of decrease in coal production is reported, namely, 6 per cent., the production of coke decreased about 60 per cent. The largest percentage of decrease is reported from the southwestern counties of Virginia, where the production in 1908 is estimated at 60 per cent. of that of 1907 , all of the decrease being attributed directly to the effects of the panic. The next largest percentage or decrease was reported from Michigan, where the production is stated to have fallen off between 25 and 35 per cent., largely as the result of slackened demand in the manufacturing cities along the Lake front, a slackening due directly to the panic. In a few of the coal-mining States the protracted drought, which began in the summer and lasted well into the winter months, caused some embarrassment. In the Southwestern States-Kansas, Oklahoma, Arkansas, and Texas-the coal production was influenced less by the financial conditions 